\title{
How sensitive is the CWSI to changes in solar radiation?
}

\author{
Nurit Agam ${ }^{\mathrm{a} *}$, Yafit Cohen ${ }^{\mathrm{b}}$, Victor Alchanatis ${ }^{\mathrm{b}}$, and Alon Ben-Gal ${ }^{\mathrm{a}}$ \\ ${ }^{a}$ Institute of Soil, Water and Environmental Sciences, Agricultural Research Organization, Gilat \\ Research Centre, Rural Delivery Negev 85280, Israel; ${ }^{b}$ Institute of Agricultural Engineering, \\ Agricultural Research Organization, Volcani Centre, P.O. Box 6, Bet Dagan 50250, Israel
}

(Received 13 December 2011; accepted 11 November 2012)

\begin{abstract}
Cloud cover drastically and instantaneously reduces net radiation and available energy. Appearance of clouds will therefore alter the surface energy balance and elicit response of plant canopy temperature $\left(T_{\mathrm{C}}\right)$. The attenuated shortwave radiation and altered $T_{\mathrm{C}}$ during the presence of clouds may subsequently affect the crop water stress index (CWSI). Therefore, to correctly interpret $T_{\mathrm{C}}$ measurements, the effect of clouds must be understood. The objective of this work was to study the effect of abrupt changes in solar radiation due to varying cloudy conditions on $T_{\mathrm{C}}$ and CWSI for olive trees. Results from two separate experiments are presented, both comparing different levels of water status of Barnea olive trees. The first experiment was conducted in a commercial orchard where five irrigation levels were applied. Thermal images were acquired simultaneously with stomatal resistance measurements on a day with clear skies. The second experiment was conducted on single trees planted in lysimeters. Irrigation was withheld for five of 15 trees for 6 days until they were severely stressed. Thereafter, irrigation was resumed to levels higher than the transpiration rates. Throughout the stress and recovery periods, water status measurements were conducted daily between 12:00 and 14:00 on all trees. On the day of maximum stress, thermal images of well-watered and stressed trees were acquired every minute throughout a time sequence during which large fluctuations in radiation due to cloud cover were observed. The most pronounced result of this study was the greater response of stressed, compared to well-watered, trees to abrupt changes in radiation intensity. When solar radiation was high, the CWSI of stressed trees reached 0.8 , while the CWSI of well-watered trees was near 0 . When solar radiation dropped due to clouds, the CWSI of the stressed trees decreased to $\sim 0.3$, while that of well-watered trees continued to fluctuate around 0 . This finding implies that application of thermal imagery for water status detection would require very high radiometric resolution and constant reference measurements. For routine monitoring in commercial olive orchards, this could be facilitated by strategic maintenance of a few well-watered trees.
\end{abstract}

\section{Introduction}

Based on the inverse correlation of canopy temperature $\left(T_{\mathrm{C}}\right)$ with transpiration (Fuchs 1990 ), $T_{\mathrm{C}}$ has long been recognized as an indicator of plant water status (Gates 1964; Berliner et al. 1984). Recent technological advances in remote thermal imaging offer the potential to acquire spatial information regarding surface temperature, and thus facilitate

\footnotetext{
*Corresponding author. Email: agam@bgu.ac.il. Present address: Wyler Department for Dryland Agriculture, French Associates Institute for Agriculture \& Biotechnology of Drylands, Jacob Blaustein Institutes for Desert Research, Ben-Gurion University of the Negev, Sede-Boker Campus, 84990, Israel.
} 
mapping of $T_{\mathrm{C}}$ variability over large areas, indirectly providing spatially distributed information of the plants' water status. However, $T_{\mathrm{C}}$ is determined not only by the water status of the plant but also by the environmental conditions, primarily incoming shortwave radiation, wind speed, and air temperature and humidity. In order to use $T_{\mathrm{C}}$ as a water status indicator, it must be normalized to account for varying environmental conditions. Such normalization is commonly applied in the form of a crop water stress index (CWSI; Idso et al. 1981; Jackson et al. 1981, 1988; Jones 1992, 1999). CWSI is a normalization of the canopy temperature to bounds of minimum and maximum values representing the temperature of a leaf transpiring at the maximum potential rate $\left(T_{\text {wet }}\right)$ and the temperature of a non-transpiring leaf $\left(T_{\text {dry }}\right)$, respectively (Jackson et al. 1981, 1988):

$$
\mathrm{CWSI}=\frac{T_{\mathrm{C}}-T_{\mathrm{wet}}}{T_{\mathrm{dry}}-T_{\mathrm{wet}}}
$$

The determination of $T_{\text {wet }}$ and $T_{\text {dry }}$ has been the subject of many publications, and both theoretical (e.g. Jackson et al. 1981, 1988; Ben-Gal et al. 2009) and empirical (e.g. Idso et al. 1981; Irmak et al. 2000; Ben-Gal et al. 2009; O’Shaughnessy et al. 2011) approaches have been suggested and applied. The theoretical approach allows the upper and lower limits to be determined by environmental conditions at the time of measurement, with only two parameters, the canopy resistance at potential evapotranspiration and the crop height, to be determined experimentally. However, this approach is valid only under conditions of full canopy cover (Jackson et al. 1988) and is therefore not suitable for determining the water status of olive trees. Empirical determination of $T_{\text {wet }}$ and $T_{\text {dry }}$, on the other hand, was proved to be useful for various crops and orchards (e.g. Irmak et al. 2000; Cohen et al. 2005; Moller et al. 2007; O'Shaughnessy et al. 2011) including olive trees (Ben-Gal et al. 2010), and was adopted in this study.

The canopy temperature reflects the surface energy conditions in which net radiation ( $R_{\mathrm{n}}$, the sum of incoming and outgoing short- and longwave radiation) plays a significant role. During daylight hours, $R_{\mathrm{n}}$ is mostly governed by solar radiation with longwave radiation representing a significantly smaller fraction. As such, $R_{\mathrm{n}}$ is very sensitive to cloud cover, which may drastically and instantaneously reduce the available energy (Kondo 1967; Brutsaert 1982). When solar radiation is reduced due to clouds, the entire surface energy balance is altered, resulting in an immediate response of canopy temperature (Turner 1991). In fact, the presence of clouds either completely blocks or to some degree attenuates both incoming and outgoing radiation. Therefore, nearly all Earth-orientated observations from space are cloud sensitive to some degree (Greaves et al. 1970). Clouds are still one of the less-understood components in the Earth-atmosphere system, and the measurement of their radiative properties remains a challenge (Pfister et al. 2003). Cloud coverage (whether partial or full) has a high frequency occurrence over the vast majority of regions around the world (excluding very dry deserts where agricultural activity is minimal). Over North America, for example, on a 3 year average, only $30 \%$ of the area was subjected to clear-sky conditions (Wylie and Menzel 1989).

Hitherto, utilization of spaceborne remote-sensing techniques under cloudy conditions is difficult or impossible. However, field or near remote-sensing techniques, where measurements are conducted close to the ground (below the clouds), are not limited to clear-sky conditions. Given the dependency of $T_{\mathrm{C}}$ on the surface energy balance, the presence of clouds and the resulting attenuated shortwave radiation alter $T_{\mathrm{C}}$ and potentially the CWSI. To correctly interpret $T_{\mathrm{C}}$ measurements, the effect of clouds must be understood. The 
objective of this work was to study the effect of abrupt changes in solar radiation due to varying cloudy conditions on $T_{\mathrm{C}}$ and CWSI for olive trees.

\section{Materials and methods}

Results from two separate experiments are presented to emphasize the potential effect of changing cloudy conditions on $T_{\mathrm{C}}$ and CWSI. Both experiments were conducted comparing different levels of water status of young Barnea olive trees.

\subsection{Clear-sky conditions experiment}

The first experiment (EXP1), described by Ben-Gal et al. (2009, 2011), was conducted in a 2 ha section of an 80 ha commercial orchard planted in 2001 near Kibutz Kfar Menachem, Israel $\left(31^{\circ} 44^{\prime} \mathrm{N}, 34^{\circ} 51^{\prime} \mathrm{E}\right)$ on 5 year-old olive trees. The experimental section was divided into complete random plots consisting of two measured trees surrounded by boundary trees. The irrigation application for each treatment was determined as a fraction of the daylighthour potential evapotranspiration $\left(\mathrm{ET}_{0}\right)$ calculated using the Penman-Monteith equation (Monteith 1965) and a canopy cover factor $\left(K_{\mathrm{C}}\right)$. Meteorological data were collected from a station located adjacent to the orchard. Irrigation levels ranged from non-stressed $\left(125-100 \%\right.$ of $\left.\mathrm{ET}_{0} \cdot K_{\mathrm{C}}\right)$ to stressed conditions $\left(50-30 \%\right.$ of $\left.\mathrm{ET}_{0} K_{\mathrm{C}}\right)$ through an intermediate level $(75 \%) . K_{\mathrm{C}}$ for the experimental period was 0.5 .

Thermal images were acquired on 23 August 2007 between 11:30 and 14:30, simultaneously with stomatal resistance measurements, such that both measurements were done at the same time on each individual tree. For each irrigation level, there were five replicate plots, with two trees measured in each plot, such that 10 trees per treatment were measured. Stomatal resistance was measured with a diffusion leaf porometer (SC-1; Decagon Devices, Inc., Pullman, WA, USA) on five leaves fully exposed to sunlight at shoulder level on each tree. Thermal images of the tree crowns were taken of six to eight individual trees of each irrigation level with an uncooled infrared thermal camera. The camera (ThermaCAM model SC2000, FLIR systems, Meer, Belgium) has a $320 \times 240$ pixel microbolometer sensor, sensitive in the spectral range of $7.5-13 \mathrm{~nm}$, and a lens with an angular field of view of $24^{\circ}$. The camera was mounted on a truck crane about $15 \mathrm{~m}$ above the canopy, yielding a spatial resolution of $2 \mathrm{~cm}$. A wet artificial reference surface (WARS) was also placed in the camera's field of view. The WARS was constructed following Meron et al. (2003), as detailed by Cohen et al. (2005), and served as a permanently wet surface of reproducible radiometric and physical properties.

Global radiation, wind speed, air temperature, and relative humidity were measured $1 \mathrm{~m}$ above the canopy by a meteorological station positioned within the experimental plot. The sampling rate was $0.1 \mathrm{~Hz}$, and $1 \mathrm{~min}$ averages were recorded by a data acquisition system (CR10X; Campbell Scientific, Logan, UT, USA).

\subsection{Cloudy conditions experiment}

In the second experiment (EXP2), detailed by Ben-Gal et al. (2010), single 2 year-old Barnea olive trees planted in fifteen $2.5 \mathrm{~m}^{3}$ volume free-standing lysimeters at the Gilat Research Centre in the northwestern Negev, Israel ( $\left.31^{\circ} 20^{\prime} \mathrm{N}, 34^{\circ} 40^{\prime} \mathrm{E}\right)$, in June 2008 were studied. The trees were irrigated daily, with quantities always exceeding (by $\sim 20 \%$ ) the previous day's transpiration rates as calculated from the weight data of the lysimeters. The 
soil surface in the lysimeters was covered by a water permeable non-woven geotextile (Non-Woven Geotextile, $500 \mathrm{~g} \mathrm{~m}^{-2}$; Noam-Urim, Kibbutz Urim, Israel) to minimize evaporation losses.

On 28 August 2009, irrigation was withheld for five of the 15 trees, and by 2 September, they were severely stressed. Thereafter, irrigation was resumed to the levels higher than the transpiration rates. Daily irrigation continued for the rest of the trees at all times. Throughout the stress and recovery periods, water status measurements were conducted daily between 12:00 and 14:00 on all trees. Canopy temperature was detected for two stressed and two well-watered trees. Instrumentation and methods for measuring stomatal resistance and canopy temperature were similar to those described for EXP1 (Section 2.1). Stomatal resistance measurements were undertaken simultaneously with imaging on the trees for which canopy temperatures were monitored, to ensure that the instantaneous measurement of stomatal resistance corresponded to the instantaneous temperature. The camera was mounted on a crane about $4.5 \mathrm{~m}$ above the canopy with the lens of $45^{\circ}$ field of view yielding a resolution of $1 \mathrm{~cm}$.

\subsection{Abrupt changes in cloud conditions}

Within the framework of EXP2 (Section 2.2), on 2 September, the day before re-watering (day of minimum available water, minimum ET, and maximum water stress), the morning hours were characterized by partial cloudy conditions. The clouds were high cirrus clouds that occasionally blocked direct solar radiation from reaching the experimental site. A time sequence 10:00-10:30 was chosen (subEXP2), during which radiation dropped from $\sim 700$ to $\sim 200 \mathrm{~W} \mathrm{~m}^{-2}$ and, after some fluctuations, increased back to $\sim 700 \mathrm{~W} \mathrm{~m}^{-2}$ (cloud sequence is marked as grey bar in Figure 1). During this sequence, the thermal camera was positioned such that it captured the crown of two trees, one well-watered and the other stressed, a continuous video was filmed, and an image was extracted and processed every minute (exemplified in Figure 2). Air temperature, solar radiation, wind speed, and relative humidity were obtained from a weather station positioned within the lysimeter site. Weather data were measured every $1 \mathrm{~s}$ and 1 min averages were logged.

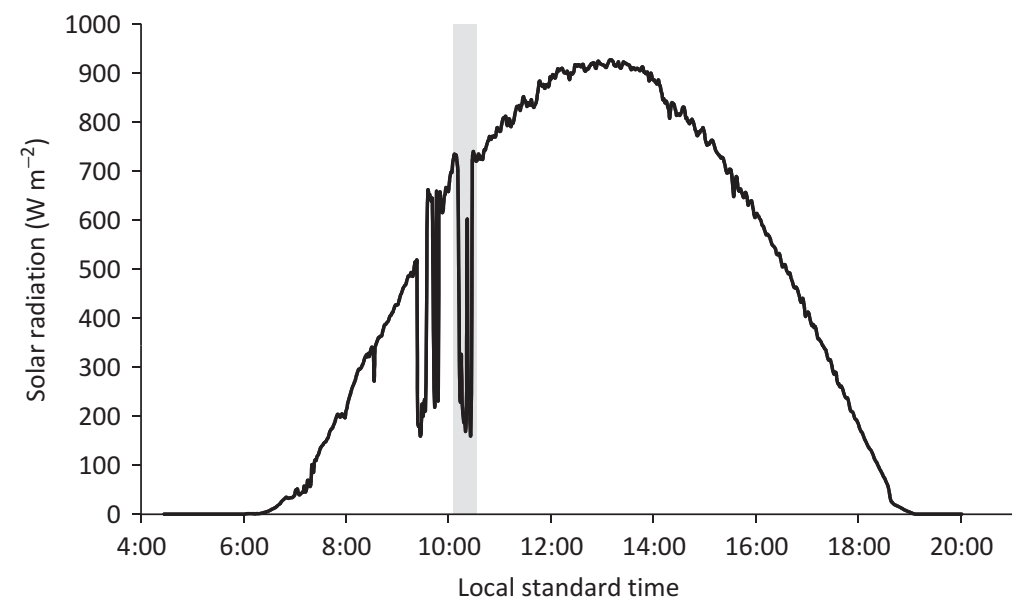

Figure 1. Solar radiation at the day of maximum stress conditions (2 September 2009). The grey area marks the time of cloud sequence analysis. 

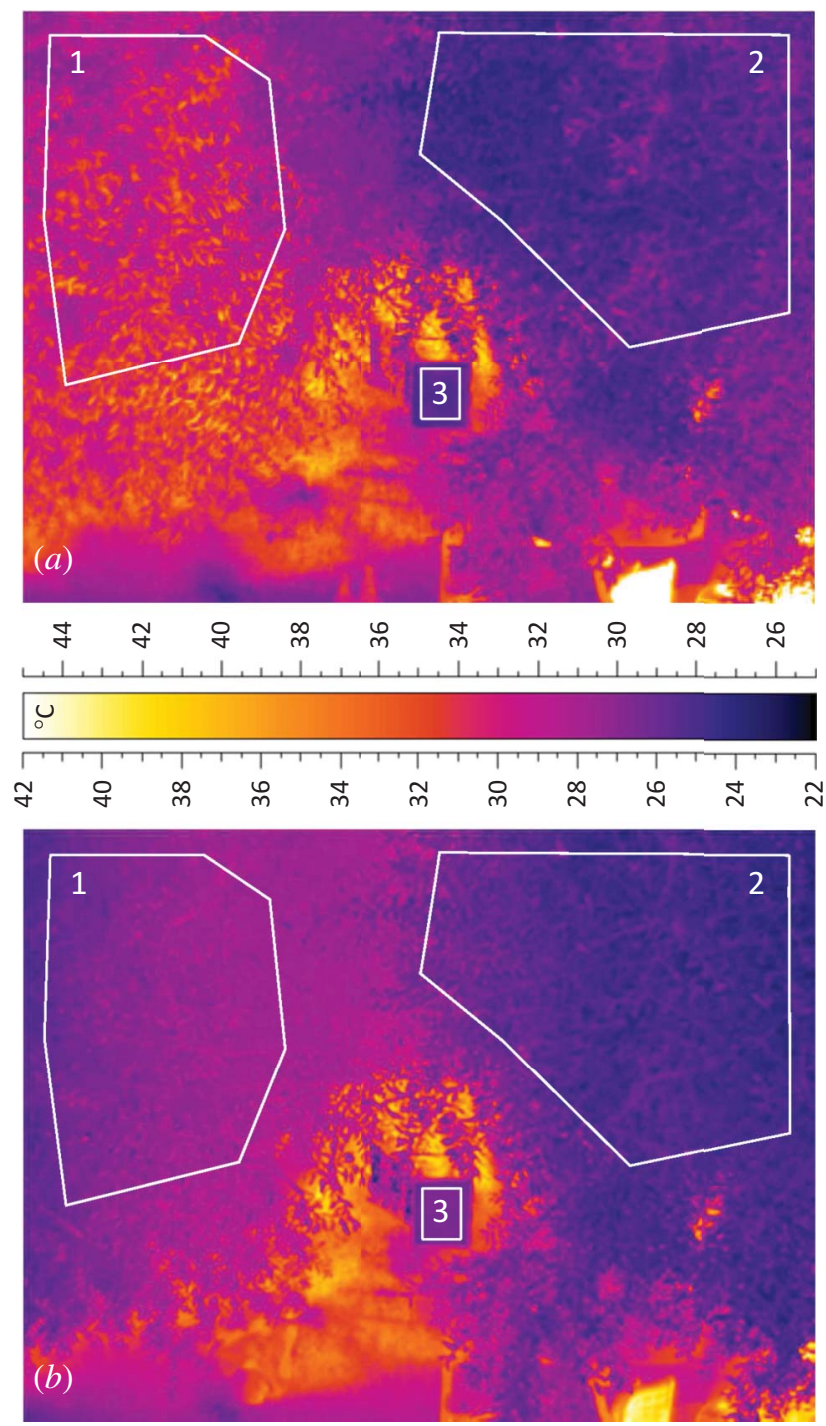

Figure 2. Example of $1 \mathrm{~min}$ thermal images extracted from the video recording. (a) Filmed at 10:10 (solar radiation $\sim 720 \mathrm{~W} \mathrm{~m}^{-2}$ ) and $(b)$ filmed at 10:16 (solar radiation $\sim 230 \mathrm{~W} \mathrm{~m}^{-2}$ ). Polygons 1 (stressed) and 2 (well-watered) in both panels mark the area from which average temperatures were determined. Rectangle 3 marks the area used to determine the wet reference temperature.

\subsection{Analysis}

CWSI was computed using Equation (1) in which $T_{\text {dry }}$ was set to $5^{\circ} \mathrm{C}$ greater than air temperature following Irmak et al. (2000) and $T_{\text {wet }}$ was determined by averaging the pixels viewing the WARS (example for sub-EXP2 is shown in rectangle 3 in Figures $2(a)$ and (b)). Detailed description of the computation procedure of CWSI for EXP1 and EXP2 are provided by Ben-Gal et al. $(2009,2010)$, respectively. In both cases, CWSI values were compared to stomatal resistance measurements to assess the ability of CWSI to detect the trees' water status. 


\section{Results}

\subsection{Correlation between CWSI and canopy resistance}

Water-stress-induced stomatal closure reduces transpiration rate, thus reducing evaporative cooling and increasing leaf temperature (e.g. Berni et al. 2009). A strong correlation is therefore expected between canopy temperature or its normalized form, the CWSI, and stomatal resistance. The day 23 August 2007 (EXP1) was characterized by conditions of clear skies (Figure $3(a)$ ) with solar radiation reaching $\sim 900 \mathrm{~W} \mathrm{~m}^{-2}$. The maximum solar radiation levels continued throughout the measurement period (11:30-14:30). In this experiment, measurements were conducted for 1 day with tree water status obtained for each of the five irrigation levels. As expected, a strong correlation $\left(r^{2}=0.85\right)$ was observed between CWSI and stomatal resistance (Figure 3(b)), showing the promise of applying the CWSI for water status monitoring of olive orchards (Ben-Gal et al. 2009).

During the second experiment (EXP2), in which a range in water status conditions was obtained by suppressing and then resuming irrigation from trees grown in lysimeters, measurements were done around noon daily for 9 days of an 11 day period. During this period, clear-sky conditions prevailed on only one day (Saturday, 29 August, when no measurements were conducted), and 1 and 2 September were mostly clear, with only some clouds in the mid-morning (Figure 4(a)). The rest of the days were characterized by varying degrees of cloudiness. The correlation between CWSI and stomatal resistance for the trees subjected to drought and recovery (Figure $4(\mathrm{~b}))$ was substantially weaker $\left(r^{2}=0.29\right.$, not significant) than that found during EXP1. Additional details, as well as correlations with other water status indicators, are presented in Ben-Gal et al. (2010). Although Ben-Gal et al. (2010) mentioned the potential effect of clouds on the results, they provided no explicit examination of this effect. We argue that to some extent, the weaker correlation between CWSI and stomatal resistance in EXP2 compared to EXP1 is due to 'less ideal' cloudy conditions in EXP2. In the next section, the effect of cloud cover on canopy temperature and CWSI is examined.

\subsection{Cloud cover effect on canopy temperature and CWSI}

Figure 5 shows the canopy temperature of both a well-watered and a water-stressed tree on the day of maximum stress during EXP2 together with solar radiation. Error bars represent

(a)

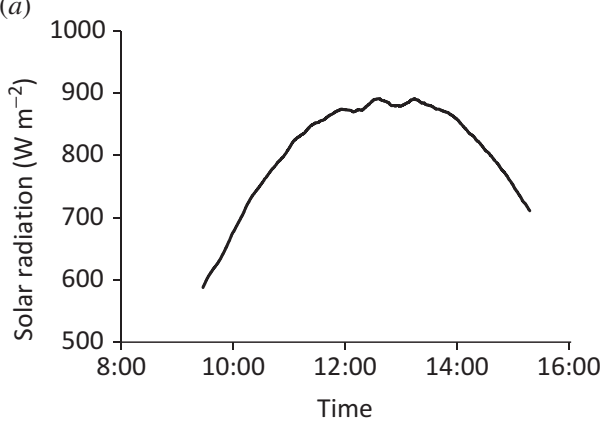

(b)

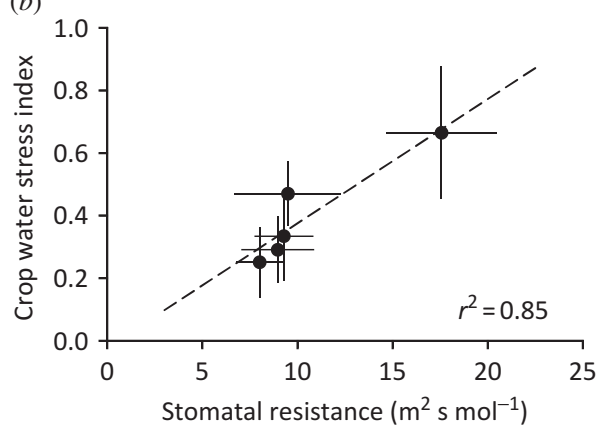

Figure 3. Solar radiation levels $(a)$ indicating clear-sky conditions, and the correlation between CWSI and stomatal resistance $(b)$ as measured in an experimental plot within a commercial orchard. Each point is the average of 10 trees per treatment. The error bars are the standard deviation of the sample. 
(a)

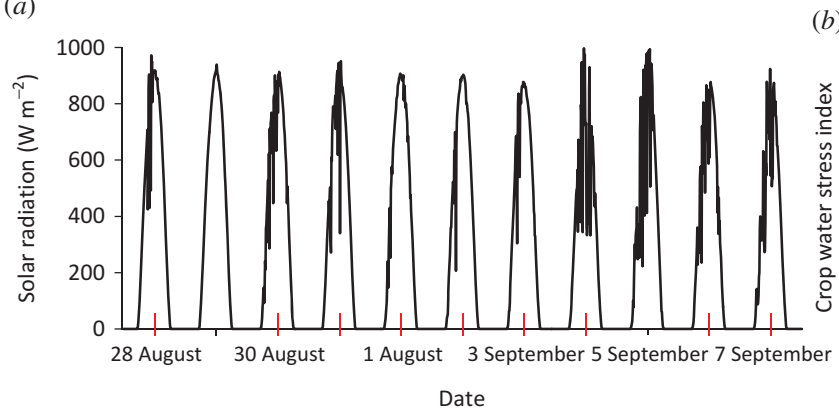

(b)

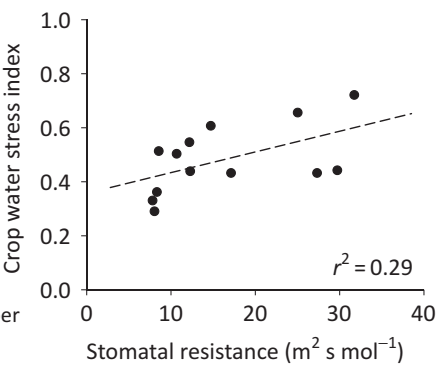

Figure 4. Solar radiation levels $(a)$ and the correlation between CWSI and stomatal resistance $(b)$ measured as the trees got into- and recovered from stress. Each data point represents an instantaneous measurement of an individual tree. Note the varying cloudy conditions resulting with a weaker correlation. The red marks indicate days during which measurements were carried out.
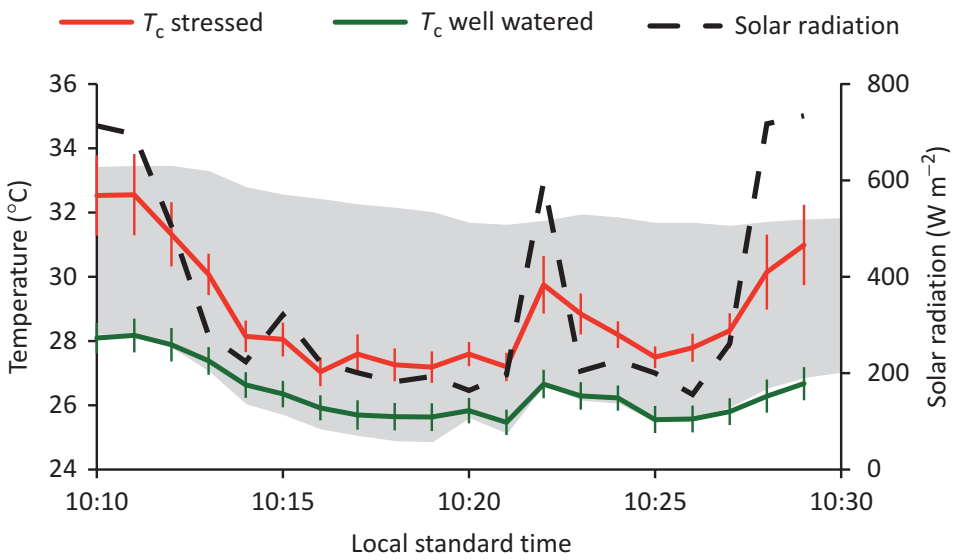

Figure 5. One-minute intervals of canopy temperature of stressed and well-watered olive trees, presented along with the solar radiation. Error bars for canopy temperatures are the standard deviation of all pixels in the image representing sunlit leaves. The area between the dry and wet boundary temperatures is greyed.

the standard deviation in $T_{\mathrm{C}}$ of all chosen pixels. A distinct and significant difference in $T_{\mathrm{C}}$ between the two trees was sustained throughout the time sequence, more so under greater solar radiation. For both the well-watered and water-stressed trees, reductions in solar radiation were immediately accompanied by reduced measures of $T_{\mathrm{C}}$, and increased radiation was associated with an immediate increase in $T_{\mathrm{C}}$. These results are similar to findings reported by Leigh et al. (2006), who showed a drop in leaf temperature within a few seconds of absent solar radiation (reaching minimum after around $17 \mathrm{~s}$ ). While the response of both trees to changes in solar radiation was immediate, the magnitude of change was larger for the stressed tree. This is reflected by the relatively invariant $T_{\mathrm{C}}$ of the well-watered tree, which was very close to the wet temperature boundary (the area between dry and wet boundary temperatures in Figure 5 is greyed). This is in contrast to $T_{\mathrm{C}}$ of the waterstressed tree which was close to the upper boundary under greater solar radiation intensity and dropped significantly when solar radiation decreased due to the presence of clouds. 


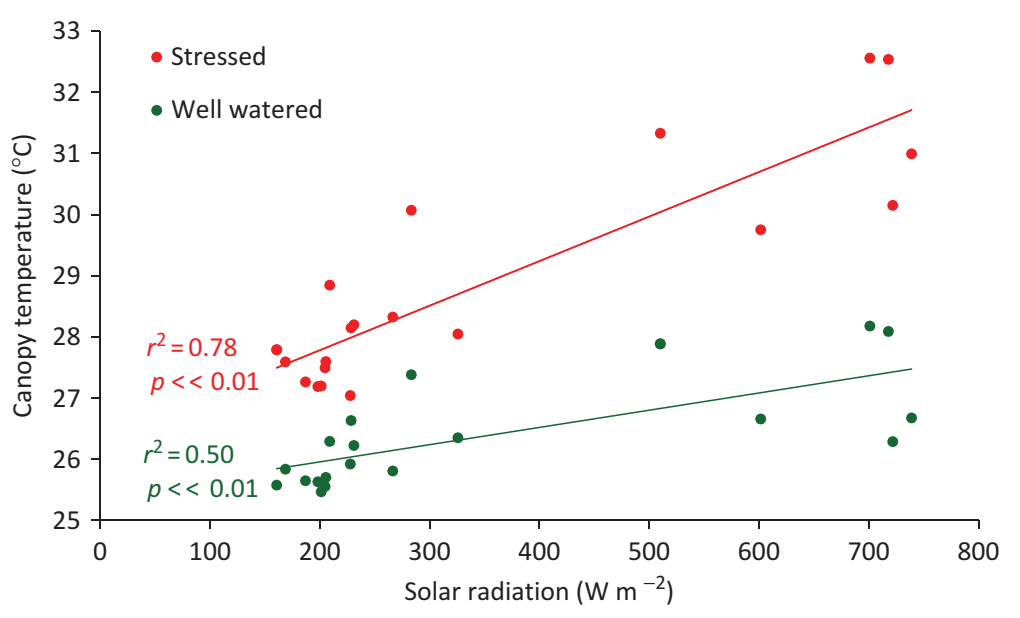

Figure 6. Scatter plot of canopy temperature of stressed and well-watered olive trees against solar radiation measured between 10:10 and 10:30 on 2 September 2009. Each point is the average of pixels representing each tree's crown temperature, measured and processed every minute during this time sequence.

The different response of the two trees is emphasized in Figure 6, where canopy temperatures are plotted against solar radiation, for the well-watered and the water-stressed trees. While both correlations were highly significant $(p<0.01)$, a stronger correlation was obtained for the stressed tree compared to the well-watered tree $\left(r^{2}=0.78\right.$ and 0.50 , respectively).

As detailed in the introduction, $T_{\mathrm{C}}$ alone is not an immediate indicator of water status. In order to be used, it must be normalized to environmental conditions, or at least be compared to a reference plant. In this study, both approaches are demonstrated. First, canopy temperature differences $\left(\Delta T_{\mathrm{C}}\right)$ between well-watered and stressed trees under varying solar radiation inputs are presented (Figure 7). The insert in Figure 7 shows a scatter plot of $\Delta T_{\mathrm{C}}$ versus solar radiation. $\Delta T_{\mathrm{C}}$ closely followed the fluctuations in solar radiation. A sharp decrease from $4.5^{\circ} \mathrm{C}$ to $1.2^{\circ} \mathrm{C}$ in $\Delta T_{\mathrm{C}}$ occurred in response to a decrease from 720 to $230 \mathrm{~W} \mathrm{~m}^{-2}$ in solar radiation over the first $3 \mathrm{~min}$. Temperature response to variations in solar radiation continued throughout the period of cloud cover and clearing, with an overall strong correlation $\left(r^{2}=0.84\right)$ between the two measures. Normalization of $T_{\mathrm{C}}$ in the form of CWSI (Figure 8) revealed a fairly constant value around 0 for the well-watered tree and large fluctuations in the values of the water-stressed tree. CWSI of the water-stressed tree was as high as 0.81 before and after events of cloud cover and as low as 0.23 when cloud presence reduced solar radiation.

\section{Discussion and conclusions}

Recent studies have shown the effectiveness of thermal images in evaluating water status of high-value irrigated orchards, particularly for vineyards (e.g. Jones et al. 2002; Grant et al. 2007; Moller et al. 2007) and olives (e.g. Ben-Gal et al. 2009; Berni et al. 2009; Sepulcre-Canto et al. 2009), where managing some level of water stress is desirable. These studies used ground images for research purposes and, in most cases, since the researchers had the privilege of choosing clear-sky conditions, good correlations of CWSI with stomatal conductance and other water status measures were found. In practice, 


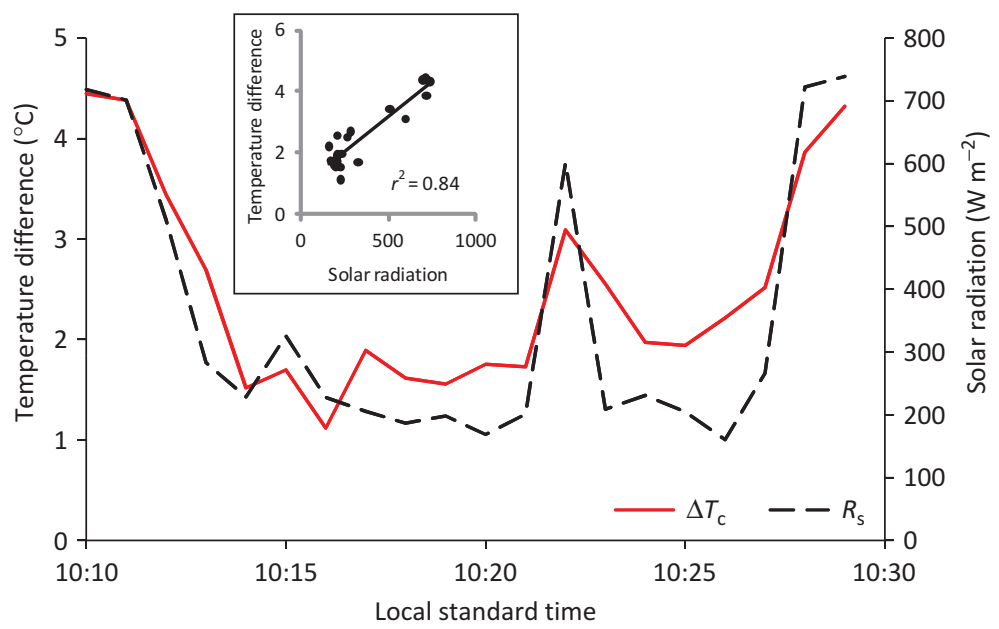

Figure 7. Differences between stressed and well-watered canopy temperatures $\left(\Delta T_{\mathrm{C}}\right)$ presented along with solar radiation. In the insert, a scatter plot of $\Delta T_{\mathrm{C}}$ versus solar radiation, for the same time span. Temperature differences were computed by subtracting the average crown temperature of the stressed tree from the average crown temperature of the well-watered tree.

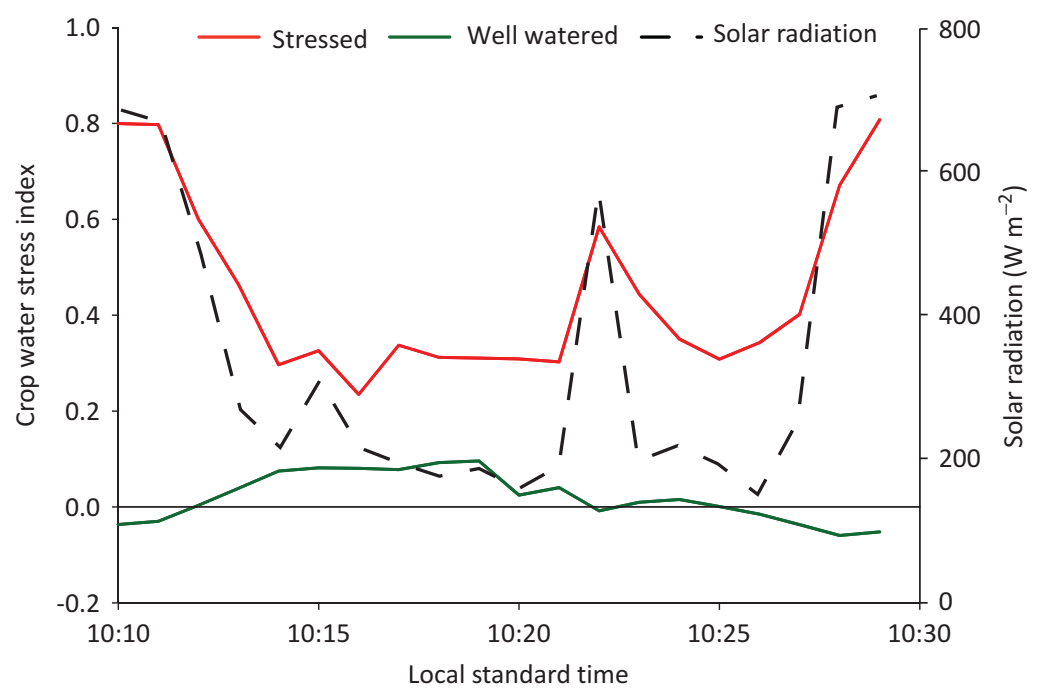

Figure 8. Crop water stress index (CWSI) of the stressed and well-watered olive trees during the period of cloud cover and retreat.

however, given the common occurrence of cloudy conditions, it is likely that routine measurements will encounter occasions of cloudy conditions. The results herein show weaker correlation between CWSI and stomatal resistance under cloudy conditions compared with those of clear skies.

The most pronounced result of this study was the greater response of water-stressed trees compared to well-watered trees to abrupt changes in radiation intensity. Similar results were reported by Jones et al. (2009) who showed a larger effect of leaf angle (as an indicator of solar radiation intensity) on the temperature of a dry leaf compared to a wet leaf. Here, 
when radiation was reduced from 700 to $200 \mathrm{~W} \mathrm{~m}^{-2}$, temperatures of well-watered and stressed trees were reduced by $2^{\circ} \mathrm{C}$ and $4.5^{\circ} \mathrm{C}$ respectively, comparably to the reductions found by Jones et al. (2009).

Since tree productivity is dependent on photosynthesis that increases with transpiration, increasing transpiration rates result in increased productivity. Hence, well-watered trees utilize most of the available energy for transpiration. Rapid changes in radiation are, therefore, highly correlated with changes in transpiration and only minor changes in canopy temperature. Assuming that $T_{\text {wet }}$ represents the temperature of a leaf transpiring at the potential rate, it is expected that the canopy temperature of a well-watered tree would follow $T_{\text {wet }}$ closely. As shown in Figure $5, T_{\mathrm{C}}$ (well-watered) and $T_{\text {wet }}$ indeed responded similarly to changes in environmental conditions in the current study, with an average difference of $0.16 \pm 0.34^{\circ} \mathrm{C}$. This resulted in a relatively stable CWSI close to 0 throughout the time sequence (Figure 8).

In contrast, trees under water stress cannot transpire at the potential rate. This results in a smaller latent and, thus, a larger sensible, heat flux manifested as an increase in canopy temperature. In this case, rapid changes in radiation, i.e. in available energy, do not drastically change transpiration rate (which is primarily governed by soil properties). Instead, they result in immediate and significant changes in canopy temperature. $T_{\text {dry }}$ is defined as a non-transpiring leaf temperature, a condition that is difficult to achieve without causing long-term damage. Therefore, while well-watered canopy temperature was expected to be similar to the lower boundary $-T_{\text {wet }}-$ it is unlikely that canopy temperature of a stressed tree would meet the upper boundary $-T_{\text {dry }}$. In fact, when solar radiation was high, canopy temperature of the stressed tree was quite close to $T_{\text {dry }}$, but when radiation dropped during cloud cover, a large gap was formed, since canopy temperature immediately dropped as well, while $T_{\text {dry }}$ barely changed.

$T_{\text {dry }}$ was empirically set to $5^{\circ} \mathrm{C}$ greater than air temperature. This empirical definition was found a reliable boundary for olive trees (e.g. Ben-Gal et al. 2009) and indeed the temperature of stressed leaves did not exceed the upper boundary (Figure 5). However, $T_{\text {dry }}$ was not sensitive to changes in solar radiation. While air temperature (and thus $T_{\text {dry }}$ ) is an aerodynamic temperature, canopy temperatures, as well as the WARS temperature, are radiometric temperatures obtained by a thermal camera. A significant number of factors determine the relationship between radiometric and aerodynamic temperatures (Kustas et al. 2007). Blyth and Dolman (1995), for example, demonstrated its dependence on available energy and relative humidity, among other environmental conditions. Similar results were reported by Lhomme et al. (1997). While canopy radiometric temperatures respond immediately to changes in solar radiation and in available energy, air temperature (and thus $T_{\text {dry }}$ ) does not respond as rapidly. This phenomenon apparently led to rapid changes in the CWSI of the stressed tree (Figure 8). In this respect, the theoretical formulation of $T_{\text {dry }}$ suggested by Jackson et al. (1981, 1988), which does account for net radiation, could have been a better approach, if the assumption of full canopy cover could be met or eliminated. Previous work shows that under partial canopy cover conditions, the empirical form of $T_{\text {dry }}$ outperforms the theoretical formulation of $T_{\text {dry }}$ proposed by Jackson et al. $(1981,1988)$ and Jones (1999), e.g. in vineyard (Moller et al. 2007), in cotton (Alchanatis et al. 2010), and in olive trees (Agam et al. 2013). Improvement of the theoretical formulation of $T_{\text {dry }}$ remains a challenge for future research.

The different response of the well-watered and stressed trees to rapid changes in radiation resulted in varying temperature differences between their canopies, which increased with radiation. Therefore, abrupt changes in solar radiation changed the magnitude of differences between well-watered and stressed trees. While CWSI normalized the canopy 
temperature to account for environmental conditions, the rapid changes in radiation were not accommodated. When solar radiation was high, the CWSI of the stressed tree was as high as 0.8 , which indeed indicated stress conditions, while the CWSI of the well-watered tree was near 0 . This yielded a difference of 0.8 between CWSI of stressed trees compared to well-watered trees. When solar radiation dropped, the CWSI of the stressed tree decreased to $\sim 0.3$, while the well-watered tree's CWSI continued to fluctuate around 0 , resulting in a significant difference but of only 0.3 , implying that while requiring very high radiometric resolution, application of thermal imagery for water status detection may remain possible under cloudy conditions. The case of water stress in orchards may be able to apply an approach used for the detection of nitrogen deficiencies in field crops where control plants are maintained and captured in images together with the rest of the field (Samborski et al. 2009). This could be managed if a number of well-watered trees to serve as a reference were maintained within commercial olive orchards. In such a case, an aerial image containing the entire section of orchard of interest is acquired, providing the canopy temperature and the CWSI of all individual trees in the image simultaneously. Trees suffering from water stress will thereby be detected by having canopy temperature significantly higher than the reference trees' temperature.

It is concluded that in its current empirical form the CWSI can reliably represent the water status of olive trees. However, even in the presence of a well-watered section within the orchard, the performance of the CWSI under cloudy conditions is weaker and the results need to be analysed carefully. Better would be to wait for clear-sky conditions.

\section{References}

Agam, N., Y. Cohen, V. Alchanatis, J. A. J. Berni, D. Kool, A. Dag, U. Yermiyahu, and A. Ben-Gal. 2013. "An Insight to the Performance of Crop Water Stress Index for Olive Trees." Agricultural Water Management 118: 79-86.

Alchanatis, V., Y. Cohen, S. Cohen, M. Moller, M. Sprinstin, M. Meron, J. Tsipris, Y. Saranga, and E. Sela. 2010. "Evaluation of Different Approaches for Estimating and Mapping Crop Water Status in Cotton with Thermal Imaging." Precision Agriculture 11: 27-41.

Ben-Gal, A., N. Agam, V. Alchanatis, Y. Cohen, U. Yermiyahu, I. Zipori, E. Presnov, M. Sprintsin, and A. Dag. 2009. "Evaluating Water Stress in Irrigated Olives: Correlation of Soil Water Status, Tree Water Status, and Thermal Imagery." Irrigation Science 27: 367-376.

Ben-Gal, A., D. Kool, Agam, N., G. E. Van Halsema, U. Yermiyahu, A. Yafe, E. Presnov, R. Erel, A. Majdop, I. Zipori, E. Segal, S. Ruger, U. Zimmermann, Y. Cohen, V. Alchanatis, and A. Dag. 2010. "Whole-Tree Water Balance and Indicators for Short-Term Drought Stress in Non-Bearing 'Barnea' Olives." Agricultural Water Management 98: 124-133.

Ben-Gal, A., U. Yermiyahu, I. Zipori, E. Presnov, E. Hanoch, and A. Dag. 2011. "The Influence of Bearing Cycles on Olive Oil Production Response to Irrigation.” Irrigation Science 29: 253-263.

Berliner, P., D. M. Oosterhuis, and G. C. Green. 1984. "Evaluation of the Infrared Thermometer as a Crop Stress Detector." Agricultural and Forest Meteorology 31: 219-230.

Berni, J. A. J., P. J. Zarco-Tejada, G. Sepulcre-Canto, E. Fereres, and F. Villalobos. 2009. "Mapping Canopy Conductance and CWSI in Olive Orchards Using High Resolution Thermal Remote Sensing Imagery.” Remote Sensing of Environment 113: 2380-2388.

Blyth, E. M., and A. J. Dolman. 1995. "The Roughness Length for Heat of Sparse Vegetation." Journal of Applied Meteorology 34: 583-585.

Brutsaert, W. 1982. Evaporation into the Atmosphere: Theory, History and Applications. Boston, MA: D. Reidel.

Cohen, Y., V. Alchanatis, M. Meron, Y. Saranga, and J. Tsipris. 2005. "Estimation of Leaf Water Potential by Thermal Imagery and Spatial Analysis." Journal of Experimental Botany 56: $1843-1852$.

Fuchs, M. 1990. "Infrared Measurement of Canopy Temperature and Detection of Plant WaterStress." Theoretical and Applied Climatology 42: 253-261. 
Gates, D. M. 1964. "Leaf Temperature and Transpiration 1." Agronomy Journal 56: 273-277.

Grant, O. M., L. Tronina, H. G. Jones, and M. M. Chaves. 2007. "Exploring Thermal Imaging Variables for the Detection of Stress Responses in Grapevine Under Different Irrigation Regimes." Journal of Experimental Botany 58: 815-825.

Greaves, J. R., P. E. Sherr, and A. H. Glaser. 1970. "Cloud Cover Statistics and Their Use in the Planning of Remote Sensing Missions." Remote Sensing of Environment 1: 95-101.

Idso, S. B., R. D. Jackson, P. J. Pinter, R. J. Reginato, and J. L. Hatfield. 1981. "Normalizing the StressDegree-Day Parameter for Environmental Variability." Agricultural Meteorology 24: 45-55.

Irmak, S., D. Z. Haman, and R. Bastug. 2000. "Determination of Crop Water Stress Index for Irrigation Timing and Yield Estimation of Corn.” Agronomy Journal 92: 1221-1227.

Jackson, R. D., S. B. Idso, R. J. Reginato, and P. J. Pinter. 1981. "Canopy Temperature as a Crop Stress Indicator.” Water Resources Research 17: 1133-1138.

Jackson, R. D., W. P. Kustas, and B. J. Choudhury. 1988. "A Reexamination of the Crop Water Stress Index." Irrigation Science 9: 309-317.

Jones, H. G. 1992. Plants and Microclimate. Cambridge: Cambridge University Press.

Jones, H. G. 1999. "Use of Infrared Thermometry for Estimation of Stomatal Conductance as a Possible Aid to Irrigation Scheduling." Agricultural and Forest Meteorology 95: 139-149.

Jones, H. G., R. Serraj, B. R. Loveys, L. Z. Xiong, A. Wheaton, and A. H. Price. 2009. "Thermal Infrared Imaging of Crop Canopies for the Remote Diagnosis and Quantification of Plant Responses to Water Stress in the Field." Functional Plant Biology 36: 978-989.

Jones, H. G., M. Stoll, T. Santos, C. De Sousa, M. M. Chaves, and O. M. Grant. 2002. "Use of Infrared Thermography for Monitoring Stomatal Closure in the Field: Application to Grapevine." Journal of Experimental Botany 53: 2249-2260.

Kondo, J. 1967. Analysis of Solar Radiation and Downward Long Wave Radiation Data in Japan. Tohoku: Tohoku University.

Kustas, W. P., M. C. Anderson, J. M. Norman, and F. Li. 2007. "Utility of Radiometric Aerodynamic Temperature Relations for Heat Flux Estimation.” Boundary Layer Meteorology 122: 167-187.

Leigh, A., J. D. Close, M. C. Ball, K. Siebke, and A. B. Nicotra. 2006. "Leaf Cooling Curves: Measuring Leaf Temperature in Sunlight." Functional Plant Biology 33: 515-519.

Lhomme, J. P., D. Troufleau, B. Monteny, A. Chehbouni, and S. Bauduin. 1997. "Sensible Heat Flux and Radiometric Surface Temperature Over Sparse Sahelian Vegetation. 2. Model for the Kb(-1) Parameter." Journal of Hydrology 189: 839-854.

Meron, M., J. Tsipris, and D. Charitt. 2003. "Remote Mapping of Crop Water Status to Assess Spatial Variability of Crop Stress: Precision Agriculture." In The Fourth European Conference on Precision Agriculture, 405-410. The Netherlands: Wageningen Academic Publishers.

Moller, M., V. Alchanatis, Y. Cohen, M. Meron, J. Tsipris, A. Naor, V. Ostrovsky, M. Sprintsin, and S. Cohen. 2007. "Use of Thermal and Visible Imagery for Estimating Crop Water Status of Irrigated Grapevine.” Journal of Experimental Botany 58: 827-838.

Monteith, J. L. 1965. Evaporation and Environment: XIX Symposium of the Society of Experimental Biology, 205-234. Cambridge: Cambridge University Press.

O'shaughnessy, S. A., S. R. Evett, P. D. Colaizzi, and T. A. Howell. 2011. "Using Radiation Thermography and Thermometry to Evaluate Crop Water Stress in Soybean and Cotton." Agricultural Water Management 98: 1523-1535.

Pfister, G., R. L. Mckenzie, J. B. Liley, A. Thomas, B. W. Forgan, and C. N. Long. 2003. "Cloud Coverage Based on All-Sky Imaging and Its Impact on Surface Solar Irradiance." Journal of Applied Meteorology 42: 1421-1434.

Samborski, S. M., N. Tremblay, and E. Fallon. 2009. "Strategies to Make Use of Plant Sensors-Based Diagnostic Information for Nitrogen Recommendations." Agronomy Journal 101: 800-816.

Sepulcre-Canto, G., P. J. Zarco-Tejada, J. A. Sobrino, J. A. J. Berni, J. C. Jimenez-Munoz, and J. P. Gastellu-Etchegorry. 2009. "Discriminating Irrigated and Rainfed Olive Orchards with Thermal Aster Imagery and Dart 3D Simulation.” Agricultural and Forest Meteorology 149: 962-975.

Turner, N. C. 1991. "Measurement and Influence of Environmental and Plant Factors on Stomatal Conductance in the Field." Agricultural and Forest Meteorology 54: 137-154.

Wylie, D. P., and W. P. Menzel. 1989. “Two Years of Cloud Cover Statistics Using VAS.” Journal of Climate 2: 380-392. 